\title{
Protective role of Annona squamosa linn bark extracts in DMBA induced genotoxicity
}

Suresh K ${ }^{1}$, Manoharn S, Blessy D

${ }^{1}$ Lecturer, Department of Biochemistry and Biotechnology, Faculty of science, Annamalai University, Tamil Nadu, India

\begin{abstract}
Background: Their has been no dearth of scientific literature that genotoxic agents have a causative effect in the pathogenesis of carcinomas. 7,12dimethylbenz(a)anthracene (DMBA) which is, a potent organ specific carcinogen has been found to produce mutagenic effects on cells ${ }^{10}$. Annona squamosa has a long history in traditional indian medicine for being used to treat several diseases including cancer.

Objective: Aim of the present study was to investigate the protective role of Annona squamosa bark extracts in DMBA induced genotoxicity in golden Syrian hamsters.

Material and methods: Genotoxicity was induced in golden Syrian hamsters by single intraperitonial injection of DMBA (30 mg/kg body weight). The antigenotoxic effect of aqueous and ethanolic bark extracts of Annona squamosa was assessed by determining the frequency of micronucleated polychromatic erythrocytes (MnPCEs) and chromosomal aberrations.

Results: The frequency of MnPCEs and chromosomal aberrations in bone marrow were higher in DMBA treated animals as compared to control animals. Oral administration of aqueous and ethanolic bark extracts significantly reduced the frequency of MnPCEs and chromosomal aberration in DMBA treated hamsters.

Conclusion: Although both extracts have shown antigenotoxic effect, the effect of ethanolic extract was found to be more prominent than the aqueous extract. The present study thus demonstrates the antigenotoxic effect of Annona squamosa bark extracts in DMBA induced genotoxicity in golden Syrian hamsters.
\end{abstract}

Key words: Genotoxicity, DMBA, Chromosomal aberrations, MnPCEs, Annona squamosa

\begin{abstract}
Nomatic cell mutation induced by genotoxic agents has been implicated in the pathogenesis of carcinogenesis ${ }^{1}$. Any change in chromosomal structure or chromosomal number due to physical or biological toxic agents is referred to as chromosomal aberrations ${ }^{2}$.Genotoxic agent's induced chromosomal abnormalities can be assessed by chromosomal aberrations frequency of micronucleated polychromatic erythrocytes (MnPCEs) ${ }^{3}$. Micronucleus originates from chromosomal fragments and/or whole chromosomes that are not included in the main daughter nuclei during nuclear division ${ }^{4}$. Assay of MnPCEs provides an indirect measure of both structural and numerical chromosomal aberrations ${ }^{5}$. Target cells for erythrocytebased micronucleus assays were traditionally obtained from the bone marrow compartment chromosome aberrations and micronucleus frequency were based on the percentage of damaged cells, rather than events per cells ${ }^{6}$. The type of aberrations induced by genotoxic agents depends on the stage of cell cycle at the time of treatment ${ }^{7}$. The bone marrow is a heterogeneous population and DNA breaks are continuously produced
\end{abstract}

during a number of DNA related process. The hamster's bone marrow micronucleus test is one of the several available in vitro mammalian test systems for the detection of the chromosomal aberrations ${ }^{8}$.

Carcinogen induced mutations in somatic cells leads to cell death and pathogenesis of several pathological conditions including cancer'. DMBA, a potent organ specific carcinogen, produced pronounced mutagenic response in several in vivo and in vitro mutation assay system $^{10}$. This carcinogen causes DNA damage by oxidizing both DNA bases and deoxyribose sugars through its active metabolite, diol epoxide ${ }^{11}$. Profound studies have documented chromosomal abnormalities during DMBA induced genotoxicity. Polyploidy and sister chromatid exchanges have been shown

\footnotetext{
Correspondence

Dr. Suresh Kathir

Lecturer, Dept of Biochemistry and Biotechnology,

Annamalai University,

Tamil Nadu, India

E-mail: suraj_cks@yahoo.co.in
} 
in DMBA induced genotoxicity ${ }^{12}$. Medicinal plants and phytochemicals are reported to have a number of protective effects ${ }^{13}$. Antigenotoxic agents exert their protective effect by inhibiting DNA adduct formation, stimulating DNA repair mechanism and Anti-oxidant functions. Antioxidants have been shown to inhibit both initiation and promotion in carcinogenesis and counteract cell immortalisation and transformation ${ }^{14}$.

Annona squamosa, belonging to family Annonacea, is used in Indian folkloric medicine to treat several diseases including cancer ${ }^{15}$. In traditional medicine the extracts of Annona squamosa barks and leaves are considered beneficial for ameliorating hyperthyroidism, diabetes and liver disorders. Previous study from our laboratory has demonstrated the chemopreventive and antilipidperoxidative potential of ethanolic extract of Annona squamosa bark in DMBA induced experimental oral carcinogenesis ${ }^{16}$.

To the best of our knowledge, there were no studies on antigenotoxic effect of Annona squamosa bark extracts in DMBA induced genotoxicity. The present study was thus designed to investigate the antigenotoxic effect of Annona squamosa bark extracts in DMBA induced genotoxicity.

\section{Materials and methods \\ Chemicals}

The carcinogen, 7, 12-dimethylbenz (a) anthracene (DMBA), was obtained from Sigma-Aldrich chemical Pvt. Ltd. Bangalore, India. All other chemicals used were of analytical grade.

\begin{abstract}
Animals
Male golden Syrian hamster 8-10 weeks old, weighing $80-120 \mathrm{~g}$ were purchased from National Institute of nutrition, Hyderabad, India and maintained in central animal house, Rajah Muthaiah Medical College and Hospital, Annamalai University. The animals were housed in poly propylene cages and provided standard pellet and water ad libitum. The animals were maintained under controlled conditions of temperature and humidity with a 12 hour light dark cycle.
\end{abstract}

\section{Plant material}

Annona squamosa bark were collected in and around Chidambaram, Tamil nadu, India and authenticated by the Botanist of Botany, Annamali University. A voucher specimen (AU04218) was also deposited.

\section{Preparation of the plant extracts}

Five hundred grams of dried and finely powdered Annona squamosa barks were soaked in $1500 \mathrm{ml}$ of 95\% ethanol overnight. The residue obtained after filtration was again re-suspended in equal volume of
$95 \%$ ethanol for 48 hours and filtered again. The above two filtration were mixed and solvent were evaporated in a rotavapour at $40-50^{\circ} \mathrm{C}$ under reduced pressure. A dark semisolid material (9\%) obtained was stored at 0 $4^{\circ} \mathrm{C}$ until used.

Hundred grams of dried and finally powdered Annona squamosa barks were suspended in $250 \mathrm{ml}$ of water for 2 hours and then heated at $60-65^{\circ} \mathrm{C}$ for 30 minutes. The extract was preserved and the process was repeated three times with the residual powder each time collecting the extract was pooled and passed through a fine cotton cloth. The above filtrate upon evaporation at $40^{\circ} \mathrm{C}$ yielded $16 \%$ semisolid extract. This was stored at $0-4^{\circ} \mathrm{C}$ until used.

A known volume of the residual extracts was suspended in distilled water and was orally administered to the animals by gastric intubation using a force-feeding needle during the experimental period.

\section{Experimental protocol}

A total number of 36 hamsters were categorized into 6 equal groups. Groups 2 and 3 animals were pre-treated with aqueous $(500 \mathrm{mg} / \mathrm{kg}$ body weight) and ethanolic (300mg/kg body weight) extracts of Annona squamosa bark extracts respectively for 5 days. At the end of the 5 th day, groups 1 to 3 animals were intraperitonealy injected with DMBA $(30 \mathrm{mg} / \mathrm{kg}$ body weight. single dose) after 2 hours administration of the bark extracts of Annona squamosa. Groups 4 and 5 hamsters received aqueous and ethanolic extracts of Annona squamosa respectively for 5 days and not administrated DMBA. Group 6 hamsters served as control and all animals provided standard pellets and water ad libitum. All the animals sacrificed at the 6 th day by cervical dislocation for the assessment of chromosomal aberrations and the frequency of micronucleated polychromatic erythrocytes (MnPCEs).

\section{Assay of MnPCEs frequency}

Bone marrow micronucleus test was carried out according to the method of Schmid ${ }^{17}$. The femur bones removed from the hamsters were cleaned and the content was flushed into tube containing $1 \mathrm{ml}$ of calf serum and was centrifuged at $500 \mathrm{~g}$ for $10 \mathrm{~min}$. The obtained pellet was suspended with few drops of fresh serum and slides were prepared and air-dried for 18 hour. After drying, the slides were stained with May-Gunwale stain followed by Giemsa stain. The frequency of MnPCEs in each group was calculated by scoring 2500 polychromatic erythrocytes (PCEs) per hamster. (Figure1)

\section{Assay of chromosomal aberrations}

Assessment of chromosomal aberrations in bone marrow was carried out according to the procedure of Kilian et $\mathrm{al}^{18}$. The femur bones were removed from 
hamsters injected intraperitonealy with $0.1 \%$ colchicines (1ml/100gm body weight) 90 minutes before sacrificing the hamsters. The bone marrow contents were flushed into $5 \mathrm{ml}$ of physiological saline and centrifuged at $500 \mathrm{~g}$ for five minutes. The sediment obtained were resuspended in $6 \mathrm{ml}$ of hypertonic potassium chloride, $\mathrm{KCl}(0.075)$ and incubated at $37^{\circ} \mathrm{C}$ for $25 \mathrm{~min}$. The pellets were than fixed using methanol: acetic acid (3:1) fixative and stained with Giemsa stain. The hundred well spread metaphase cells were scored for each hamster and structural chromosomal aberrations were observed and recorded. (Figure 2)

\section{Results}

The frequency of MnPCEs and chromosomal aberrations in control and experimental animals are given in Table 1 and 2 respectively. Hamster treated with DMBA (Groups 1to3) showed higher frequency of MnPCEs and chromosomal aberrations (chromosomal gap, chromatid break, chromosomal break, fragment, and minute) as compared to control hamsters (Group6). Hamster treated with DMBA alone (Group1) showed highest frequency of MnPCEs and chromosomal aberrations as compared to control hamsters. Oral pretreatment with aqueous and ethanolic extract of Annona squamosa bark for 5 days to DMBA treated animals significantly reduced the frequency of MnPCEs and chromosomal aberrations (Groups 2 and 3 respectively). Oral pretreatment of aqueous and ethanolic extracts of Annona squamosa bark extracts alone (Groups 4 and 5 respectively), displaying no significant results were observed as compared to control hamsters

Table 1: Effect of Annona Squamosa Linn. on DMBA-induced bone marrow micronuclei formation

\begin{tabular}{|c|l|c|c|c|}
\hline Group & \multicolumn{1}{|c|}{ Parameters } & MnPCEs / 2500 PCEs & PCEs/NCEs & PCEs* $(\%)$ \\
\hline 1. & DMBA & $56.9 \pm 4.2^{\mathrm{b}}$ & $0.76 \pm 0.07^{\mathrm{b}}$ & 43.18 \\
\hline 2. & DMBA + AsABet & $32.5 \pm 4.1^{\mathrm{c}}$ & $0.83 \pm 0.05^{\mathrm{c}}$ & 47.08 \\
\hline 3. & DMBA + AsEBet & $24.9 \pm 2.7^{\mathrm{d}}$ & $0.94 \pm 0.06^{\mathrm{d}}$ & 47.36 \\
\hline 4. & AsABet alone & $5.19 \pm 0.22^{\mathrm{a}}$ & $1.02 \pm 0.06^{\mathrm{a}}$ & 50.48 \\
\hline 5. & AsEBet alone & $5.21 \pm 0.25^{\mathrm{a}}$ & $1.03 \pm 0.04^{\mathrm{a}}$ & 50.64 \\
\hline 6. & Control & $5.22 \pm 0.29^{\mathrm{a}}$ & $1.03 \pm 0.05^{\mathrm{a}}$ & 50.73 \\
\hline
\end{tabular}

Values are expressed as mean $\pm \mathrm{SD} ; \mathrm{n}=6$. Values not sharing a common superscript significantly differ at $\mathrm{P}<0.05$. (DMRT).

* Percentage of polychromatic erythrocytes was calculated as follows: [PCEs / (PCEs+NCEs) x 100.

AsABet - A.squamosa aqueous bark extract. AsEBet - A.squamosa ethanolic bark extract.

Table 2: Mitotic index and frequencies of chromosomal abnormalities in experimental and control animals

\begin{tabular}{|c|c|c|c|c|c|c|c|c|c|}
\hline \multirow[b]{2}{*}{ Group } & \multirow[b]{2}{*}{ Parameters } & \multirow{2}{*}{$\begin{array}{c}\text { Mitotic } \\
\text { index (\%) }\end{array}$} & \multicolumn{5}{|c|}{ Chromosomal aberrations Hamster $^{-1}$} & \multirow{2}{*}{$\begin{array}{c}\text { Total } \\
\text { aberrations } \\
\text { Hamster }^{-1}\end{array}$} & \multirow{2}{*}{$\begin{array}{c}\text { Abnormal } \\
\text { metaphase } \\
\text { Hamster }^{-1}\end{array}$} \\
\hline & & & $\mathbf{G}^{*}$ & B' & B” & $\mathbf{F}$ & $\mathbf{M}$ & & \\
\hline 1. & DMBA & $1.89 \pm 0.07^{\mathrm{b}}$ & $10.38 \pm 0.21^{\mathrm{b}}$ & $6.32 \pm 0.3^{\mathrm{b}}$ & $2.11 \pm 0.13^{\mathrm{b}}$ & $6.84 \pm 0.8^{b}$ & $2.02 \pm 0.19^{\mathrm{b}}$ & $17.6 \pm 1.32^{\mathrm{b}}$ & $13.4 \pm 1.43^{\mathrm{b}}$ \\
\hline 2. & $\begin{array}{l}\text { DMBA + } \\
\text { AsABet }\end{array}$ & $2.49 \pm 0.86^{\mathrm{c}}$ & $6.96 \pm 0.08^{\mathrm{c}}$ & $4.56 \pm 0.23^{\mathrm{c}}$ & $1.42 \pm 0.07^{\mathrm{c}}$ & $4.74 \pm 0.4^{c}$ & $1.43 \pm 0.09^{\mathrm{c}}$ & $10.1 \pm 1.3^{\mathrm{c}}$ & $8.5 \pm 0.93^{c}$ \\
\hline 3. & $\begin{array}{l}\text { DMBA + } \\
\text { AsEBet }\end{array}$ & $3.39 \pm 0.5^{\mathrm{d}}$ & $4.39 \pm 0.09^{\mathrm{d}}$ & $3.39 \pm 0.16^{\mathrm{d}}$ & $1.01 \pm 0.05^{\mathrm{d}}$ & $3.21 \pm 0.42^{\mathrm{d}}$ & $1.06 \pm 0.07^{\mathrm{d}}$ & $6.81 \pm 0.98^{\mathrm{d}}$ & $5.48 \pm 0.64^{\mathrm{d}}$ \\
\hline 4. & $\begin{array}{l}\text { AsABet } \\
\text { alone }\end{array}$ & $4.33 \pm 0.76^{\mathrm{a}}$ & $0.44 \pm 0.03^{\mathrm{a}}$ & $1.25 \pm 0.07^{\mathrm{a}}$ & $0^{\text {a }}$ & $1.30 \pm 0.10^{\mathrm{a}}$ & $0.28 \pm 0.03^{\mathrm{a}}$ & $2.82 \pm 0.31^{\mathrm{a}}$ & $1.47 \pm 0.14^{\mathrm{a}}$ \\
\hline 5. & $\begin{array}{l}\text { AsEBet } \\
\text { alone }\end{array}$ & $4.36 \pm 0.59^{\mathrm{a}}$ & $0.43 \pm 0.04^{\mathrm{a}}$ & $1.22 \pm 0.06^{\mathrm{a}}$ & $0^{\text {a }}$ & $1.27 \pm 0.01^{\mathrm{a}}$ & $0.26 \pm 0.02^{\mathrm{a}}$ & $2.75 \pm 0.33^{\mathrm{a}}$ & $1.45 \pm 0.12^{\mathrm{a}}$ \\
\hline 6. & Control & $4.37 \pm 0.98^{\mathrm{a}}$ & $0.42 \pm 0.03^{\mathrm{a}}$ & $1.23 \pm 0.04^{\mathrm{a}}$ & $0^{\text {a }}$ & $1.29 \pm 0.1^{\mathrm{a}}$ & $0.27 \pm 0.02^{\mathrm{a}}$ & $2.73 \pm 0.34^{\mathrm{a}}$ & $1.43 \pm 0.11^{\mathrm{a}}$ \\
\hline
\end{tabular}

Values are expressed as mean $\pm \mathrm{SD} ; \mathrm{n}=6$. Values not sharing a common superscript significantly differ at $\mathrm{P}<0.05$. (DMRT) G-Gap, B- Chromatid Break, B"- Iso chromatid Break, F-fragment, M-Minute. A-Mitotic index has been calculated by analyzing 100 cells/animal (for the mitotic cells calculated for each group.B-frequency per 100 cells. Each chromosomal aberration has been counted by analyzing 100 cells/animals ( 6 animals/group, for a total of 600 cells/group) and mean \pm were calculated per group. C-Gaps were not included in total chromosomal aberration AsABet - A.squamosa aqueous bark extract. AsEBet - A.squamosa ethanolic bark extract. 


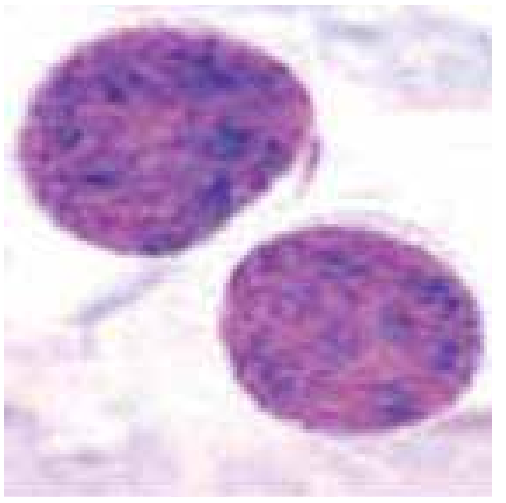

A

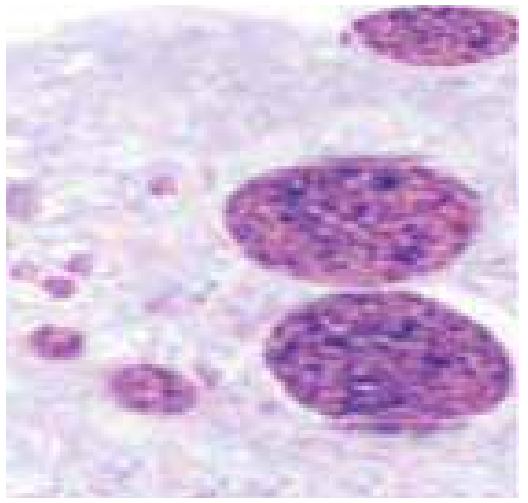

B

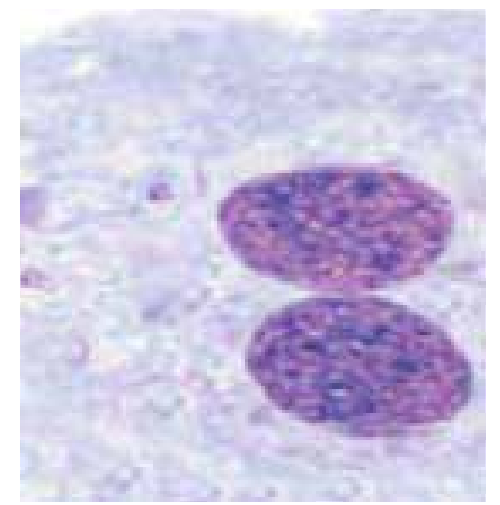

C

Fig 1: Effect of Annona Squamosa Linn. On DMBA-induced bone marrow micronuclei formation (100x Magnification)

A- Control, B- DMBA Treated, C- DMBA+ A.squamosa ethanolic bark extract treated

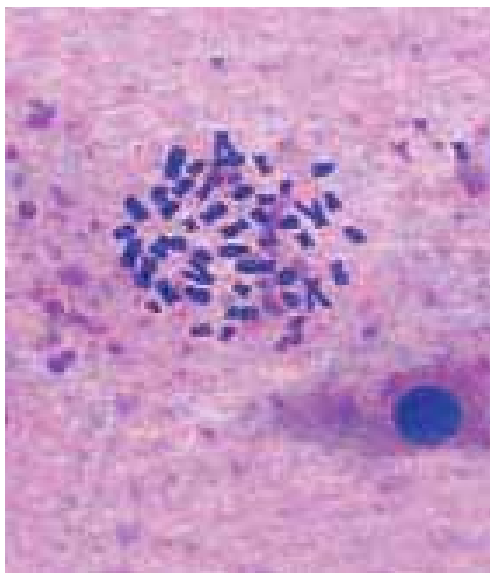

$\mathbf{A}$

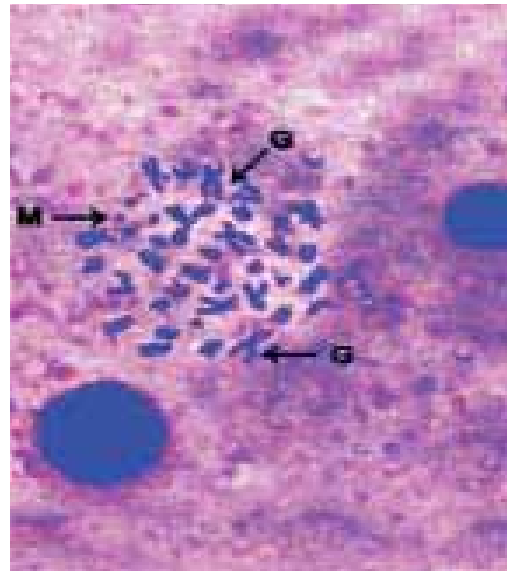

B

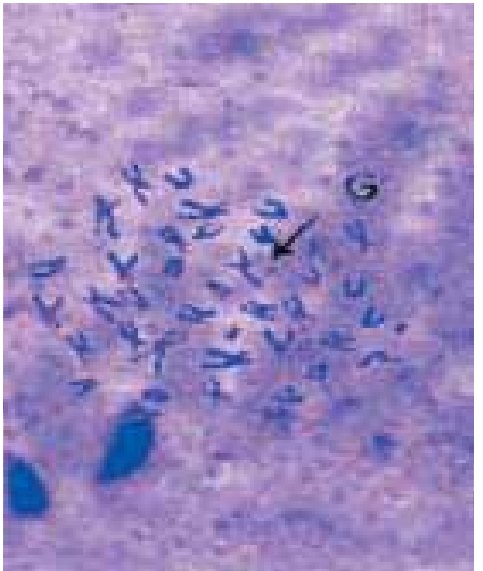

C

Fig 2: Mitotic index and frequencies of chromosomal abnormalities in experimental and control animals. (100x Magnification)

A- Control, B- DMBA Treated, C-DMBA+ A.squamosa ethanolic bark extract treated.

\section{Discussion}

Genetic instability is a common phenomenon in the conversion of normal cell to malignant cell. Such instability can results from changes in chromosome structure, error in DNA repair mechanisms or due to replication of $\mathrm{DNA}^{19}$. Cancer cells are characterized by having aberrant chromosomes. Altered MnPCEs frequency and chromosomal aberrations, important indicator of genetic instability, could have a predictive value for cancer development ${ }^{20}$. In the present study, we have observed a significant increase in MnPCEs frequency and marked chromosomal aberrations in the bone marrow of DMBA alone treated hamsters ${ }^{21}$. Several studies have documented that DMBA can induce genetic alterations as well as carcinogenesis. DMBA can cause chromosomal damage by binding with adenine residues of DNA through its activemetabolite diol epoxide and other free radicals formed during metabolic activation ${ }^{22}$. Experimental studies have demonstrated N-ras mutation, H-ras mutation and A to T transversion in H-ras mutation codon 61 in experimental carcinogenesis $^{23}$. Elevated MnPCEs frequency and percentage of chromosomal aberrations were shown during DMBA induced genotoxicity. Our study corroborates these observations ${ }^{24}$. Oral pre-treatment of aqueous and ethanolic extracts of Annona squamosa bark for 5 days significantly reduced the frequency of MnPCEs and abnormalities of chromosomal structure in DMBA treated hamsters. The possible mechanisms for the protective effect of Annona squamosa bark extracts include enhancing the antioxidant defence mechanism 
to neutralize the toxic effects of reactive oxygen species generated by DMBA. Our results therefore indicate that Annona squamosa bark extracts have potent antigenotoxic effect in DMBA induced genotoxicity. Although both extract have shown antigenotoxicity effect, the ethanolic extract was found to be more potent than the aqueous extract, the ethanolic bark extract contains higher amount of non-enzymic anti oxidants like vitamin E, B12, C, niacin and bioactive compounds such as squamoline, oxosimicone, bullacin- $\mathrm{B}^{25}$. The present study thus demonstrates the antigenotoxic effect of Annona squamosa bark extracts in DMBA induced genotoxicity. Although the exact mechanisms of the antigenotoxic effect of Annona squamosa bark extract is unclear, its chemo preventive, antilipidperoxidative and antioxidant properties may play a possible role.

\section{Conclusion}

The present study has demonstrated the protective role of Annona squamosa bark extracts in DMBA induced genotoxicity in male Syrian golden hamsters. The possible mechanism for the protective effects of Annona squamosa bark extracts include enhancing the antioxidant defense mechanism to neutralize the toxic effects of reactive oxygen species generated by DMBA. Although both extracts have shown antigenotoxic effect, the ethanolic extract was found to be more potent than aqueous extract.

\section{References}

1. Nersesion AK, Zil'fan VN, Kumkumdhzian VA. An analysis of the micronuclei in the mucosa of cancer patients for assessing the clastogenic effect of chemical preparations. Tsitol. Genet.1993; 27: 77-80.

2. Kayal JJ, Triedi AH, Dave J, Nair SV, Bhide UC, Goswami SG. Mucosa of users of tobacco products singly or in various combinations. Mutagenesis. 1993; 8:31-3.

3. Hakura A. Genotoxicity tests as a safty study required for the development of pharmaceuticals: Nippon yakurigaku Zasshi. 2007 July 13; 130: 57-61.

4. Fenech M, Holland N, Chang WP, Zelger E, and Bonassi, S. The human micronucleous projectAn international collaborative study on the use of micronuclei technique for DNA damage in humans. Mutat. Res. 1999; 428:271-83.

5. Wagnschaffe U, Bitsch A, Kielhorn J, and Mangelsdorf I. Mutagenecity testing with transgenic mice. Part 1: Comparison with the mouse bone marrow micronucleus test. J Carcinog. 2005; $4: 3$.
6. Allen B, Zeiger E, Lawrence G, Friedman, and Shipp A. Dose-response modeling of invivo genotoxicity data for use in risk assessment: some approaches illustrated by an analysis of acrylamide. Regul. Toxicol. Pharmacol. 2005; 41-27.

7. Wary KK, Sharon RN. Aqueous extract of betal nut of northeast India induced DNA-shared breaks and enhances rate of cell proliferation in vitro. Effects of betel-nut extract in vitro, J.Cancer Res. Clin.Oncol. 1988; 579-82.

8. Stitich HF, San HC, Rosin MP. Adaption of the DNA-repair and micronucleus test to human cell suspensions and exfoliated cells. Ann. N.Y. Acad. Sci. 1983;27:77-80.

9. Ames N, Durston WE, Yamasaki E, and Lee FD. Carcinogens are mutagens: a simple test system combining liver homogenates for activation and bacteria for detection. Proc. Natl. Acad. Scl. USA. 1973; 70: 2281-3.

10. Chang KW, Lin SC, Koss S, Pathi K, Solt D. P53 and Ha-ras mutations in chemically induced hamster buccal pouch carcinomas carcinogenesis. 1996; 17:595-600.

11. Han EH, Hwang YP, Jeong TC, Lee SS, Shin JG, JeongHG. Eugenolinhibit 7, 12-dimethylbenz(a) anthracene-induced genotoxicity in MCF- 7 cells: Bifunctional effects on CYPI and NAD (P) H: quinine oxido reductase. FEBS lett. 2007; 581: 749-56.

12. Guerin MR, Energy sourced of polycyclic aromatic hydrocarbons. In: Gelboin HV and TS OPOP (eds), Polycyclic hydrocarbon and cancer:Chemistry, Molecular biology and environment. New York: Academic press; 1978. $1-42$.

13. Wang Z, Polavaram R, Fuentes CF, Shaphay SM. Topical Chemoprevention of oral cancer with tretinoin biofilm Arch. Otolaryngol. Head and neck surg. 2003;129:869-2003.

14. Chandra, M., Bhuvaneswari KVP, Abraham SK, Nagini S. Dose- Dependent protection of tomato against 7, 12-dimethylbenz(a)anthracene Induced genotoxicity and oxidative stress in mice. J. Med. Food. 2003; 6:169-73.

15. Joshi SG, Oleacene. In: Medicinal plants. Oxford and IBH publishing Co. Pvt. Ltd. New delhi, 2000, p 216.

16. Suresh K, S.Manoharon K, Panjamurthy and K.Kavitha-Chemopreventive and AntilipidPeroxidative efficacy of Annona squamosa bark extracts in experimental oral carcinogenesis. Pak J Biol Sci. 2005; 9:2600-5. 
17. Schmid W.The micronucleous test. Mutat Res.1975; 31:9-15.

18. Killian DJ, Moreland FM, Benge MC, Legator MS, Whorton EB. A collaborative study to measure interlaboratory variation with the invivo bone marrow metaphase procedure. In: Kilbey Bj, Legator M, Nichols W, Romel C. Eds. Handbook of mutagenicity test procedures. Elsevier/North- Holland, Amsterdom: Elsevier; 1977; 243-60.

19. Legator MS, Auww. Application of integrated genetic monitoring: The optimak approach for detecting environmental carcinogens. Environ. Health perspect. 1994; 102: 125-32.

20. Miyamoto CT, Sant'anna JR, Franco CC, CastroPrado. (Genotoxicity mitotic recombination) of the cancer chemotherapeutic agent's cisplatin and cytosine, Food. Chem. Toxicol. 2007; 45: 1091-5.

21. Bhuvaneswari V, Velmurugan B, Abraham SK and Nagini S. Tomato and garlic by gavage modulate 7,12-dimethylbenz[a]anthracene induced genotoxicity and oxidative stress in mice, Braz. J. Med. Biol. Res. 2004; 37: 102934.
22. Manjanatha MG, Shelton SD, Aidoo A, Lyncook LE, Cascino DA. Comparison of invivo mutagenesis in the endogenous Hprt gene and the lac I tran gene of Big Blue (R) rats treated with 7,12-dimethylbenz(a)anthracene. Mutat. Res.1998; 401,165-78.

23. Osaka M, Matsuo S, Koh T, Sugiyama T. Specific $\mathrm{N}$-ras mutation in bone marrow within $48 \mathrm{H}$ of 7,12-dimethyl benz(a) anthracene treatment in Muggins-Sugiyama rat leukemogenesis. Mol. Carcinog. 1996; 126-31.

24. Manoharan S, Panjamurthy K, Vasudeven K, Sasikumar D, Kolanjiappan K. Protective effect of Jasminum grandiforum Linn. On DMBAInduced chromosomal aberrations in Bone marrow of Wister Rats. Int J Pharmacol. 2006; 2: 406-10.

25. Hopp DC, Alali FQ, Gu ZM, McLaughlin JL. Three new bioactive bis/adjacent THF/ring acetogenins from the bark of Annona squamosa. Bioorg Med Chem. 1998; 6(5):569-75. 